\title{
El gasto militar en Colombia: aspectos macroeconómicos y microeconómicos
}

\section{Yaneth Giha Tobar}

Economista, Analista de la División de Fuerzas Militares

y Policía, Depto. Nacional

de Planeación,

Colombia

\section{Héctor Riveros Reyes}

Economista, Analista de

la misma División

\section{Andrés Soto Velasco}

Politólogo, Jefe de la

Unidad de Justicia y Seguridad,

Dpto. Nacional de Planeación
En este artículo se analiza el gasto en defensa y seguridad (GDS) en Colombia, bajo la premisa de que para apreciar mejor el efecto de dicho gasto en el crecimiento económico y las finanzas públicas es conveniente analizar su composición interna, ya que ella permite inferir su impacto sobre la producción de la defensa y la seguridad. Para este fin, se pasa revista a los desarrollos teóricos sobre las repercusiones del gasto militar y se analiza el gasto en defensa y seguridad en Colombia, sobre la base de información de la Contraloría General de la República. Se examina asimismo la eficiencia del gasto militar y de la Policía Nacional, particularmente las relaciones combateapoyo y ataque-defensa, demostrando así la necesidad de reorganizar los efectivos militares. En las conclusiones se proponen diversas formas de obtener ahorros en el presupuesto de defensa. Los más significativos están asociados al manejo de personal, ya que los gastos de nómina representan el 73\% del gasto total. $\mathrm{Al}$ respecto, se propone modificar el régimen de prestaciones, aumentar la edad de retiro, disminuir el número de efectivos y reestructurar la relación entre fuerzas de combate y personal de apoyo y administrativo. 
I

\section{Introducción}

El conflicto armado en Colombia ha originado debates sobre el gasto en defensa y seguridad (GDS). Quienes favorecen este gasto estiman que el GDS es fundamental para fortalecer a la Fuerza Pública, que el mejoramiento de las fuerzas de seguridad del Estado eleva las probabilidades de consolidar un entorno de paz y tranquilidad en donde predominen las garantías individuales, y que influye positivamente en la demanda y el empleo. Sus críticos, en cambio, argumentan que el GDS es improductivo; que más que mejorar el entorno social limita los recursos públicos disponibles para invertir en áreas de mayor impacto social, y que además Colombia está haciendo un esfuerzo económico desproporcionado debido al actual conflicto armado.

Pese a que estos planteamientos parten de premisas aparentemente incontrovertibles, este artículo pretende analizar los postulados subyacentes. Comenzaremos por hacer un resumen del debate en torno a los efectos del GDS sobre la economía. Quienes piensan que el GDS es improductivo parten de la premisa de que cualquier erogación en este campo tiene efectos negativos sobre la economía y además desplaza recursos que de otro modo generarían mayor valor agregado. Sin embargo, para poder determinar si la racionalización del GDS verdaderamente da un dividendo de paz, es necesario saber cuál es el impacto de este gasto sobre la economía. Para que la racionalización tenga sentido económico, el beneficio generado por el ahorro en GDS destinado a áreas diferentes a la seguridad debe ser mayor que el impacto del propio GDS.

De los estudios internacionales sobre gasto mili$\operatorname{tar}^{1}$ realizados a partir de los años setenta se desprende que los resultados en esta materia no son conclu-

\footnotetext{
$\square$ Los autores agradecen la coordinación de Luis Jorge Garay y los comentarios de Gabriel Piraquive Galeano. Lo expresado en este artículo es responsabilidad de los autores y no refleja necesariamente los puntos de vista de la institución a la que pertenecen ni de otros organismos gubernamentales.

1 En este artículo se homologa la definición de gasto militar con la de gasto en defensa y seguridad (GDS) y gasto en Fuerza Pública (GFP). Se hace así porque desde 1950 el presupuesto de la Policía Nacional está incorporado al presupuesto del Ministerio de Defensa y, de acuerdo con la definición de gasto militar de la Organización del Tratado del Atlántico Norte (OTAN), que hemos utilizado aquí, la Policía realiza actividades que demandan recursos propios de este gasto.
}

yentes. No obstante, debe tenerse en cuenta que debatir sobre el nivel óptimo de GDS no es un ejercicio abstracto, pues en el fondo los recursos económicos son los medios provistos para alcanzar un fin a través de medios militares. Por ello es necesario compaginar tanto las repercusiones en materia de seguridad como las consecuencias financieras y económicas del gasto.

El análisis de la situación colombiana parte de la percepción ampliamente difundida de que el esfuerzo que realiza Colombia para hacer frente al conflicto armado es desproporcionadamente alto. En gran medida, tal percepción puede deberse a la creciente sensación de que los objetivos de seguridad del país parecen cada vez más lejanos, mientras los recursos financieros, económicos y sociales destinados a lograrlos son cada vez mayores. Sin embargo, quedarse sólo en el análisis del GDS a la luz de su posible impacto sobre las finanzas del Estado resulta insuficiente. Es la composición interna de dicho gasto la que, en definitiva, permite inferir el efecto real de éste sobre la producción de la defensa y la seguridad, que es su objetivo final. Examinar este aspecto genera una base más sólida para realizar el análisis macroeconómico.

Con este fin, se hace aquí un examen pormenorizado del GDS en Colombia, considerando los informes de la Contraloría General de la República. La información desglosa los recursos para funcionamiento e inversión, es decir, los gastos destinados al pago de nómina y pensiones tanto del personal civil como del militar, los gastos generales, y aquellos destinados a la formación del capital militar y policial. Para el caso específico de Colombia, esta erogación se denominará gasto en Fuerza Pública (GFP). Dicho rubro comprende todo el gasto realizado en las Fuerzas Militares (incluido el funcionamiento del Ministerio de Defensa y de otros organismos comprometidos en proyectos de defensa) y el gasto en fuerzas de policía y fuerzas militares auxiliares organizadas en caso de conflicto. El propósito de pormenorizar el GFP es determinar la orientación que a éste se le ha dado en Colombia, para lo cual se establece su comportamiento histórico y se identifican sus componentes estructurales y coyunturales.

Además, se señala que la reducción de costos en el sector sólo es posible si se efectúan cambios en el manejo del personal y en la administración de los re- 
cursos físicos. Mejorar la forma en que se aplica la acción de la Fuerza Pública permite aumentar la capacidad de proveer defensa y seguridad. El análisis microeconómico del sector ofrece la oportunidad de explorar posibles opciones para que en Colombia el GFP se traduzca en mayores niveles de defensa y seguridad, y a la vez dimensionar la capacidad de reducirlo y hacerlo más eficiente.

\section{II}

\section{Análisis teórico del impacto económico del gasto militar}

Desde 1973 se ha venido dando una fuerte controversia en relación con el impacto del gasto militar sobre el crecimiento económico. Algunos sostienen que este gasto es improductivo, argumentando que cualquier erogación en este campo genera efectos negativos sobre la economía y limita los recursos públicos disponibles para invertir en áreas de mayor beneficio social. Otros, en cambio, creen que el gasto militar favorece el crecimiento económico en cuanto contribuye de manera significativa a acrecentar la capacidad productiva nacional.

Quienes argumentan que existe una relación negativa entre el gasto militar y los indicadores de desarrollo económico y social afirman que, aunque este gasto constituye una estrategia necesaria para el sistema capitalista, tiene un impacto adverso en la tasa de crecimiento porque provoca menores niveles de inversión.

En recientes estudios se ha venido escudriñando los efectos macroeconómicos del gasto militar en los países menos desarrollados. Se ha comprobado que afecta adversamente el crecimiento, la balanza de pagos en cuenta corriente, el ahorro y la inversión. Además, se ha observado una diferencia significativa entre el nivel de gasto realizado por dictaduras militares y el efectuado por gobiernos civiles. Dichos estudios concluyen que si la seguridad de una nación depende del crecimiento económico, entonces el gasto en sus Fuerzas Militares parece estar comprando tanto inseguridad como subdesarrollo (Smith, 1977; Deger, 1986; Nabe, 1983; Ball, 1983; Leontief y Duchin, 1983; Pivetti, 1992).

La mayoría de las naciones en desarrollo se encuentran apremiadas por equilibrar sus recursos fiscales en medio de las crecientes demandas de sus costosas fuerzas armadas. Es así como, según algunos teóricos, se ha venido desarrollando el fenómeno del maltusianismo militar: es decir, la confrontación entre pe- queños aumentos anuales de los recursos fiscales y aumentos geométricos en los costos asociados con la defensa. En muchos países, los costos de provisión del aparato militar superan su capacidad para pagarlos. Por múltiples razones, desde los años setenta se ha venido dando un círculo vicioso. Al aumentar la burocracia militar, se adquieren equipos militarmente inútiles y cada vez más costosos, lo que provoca un desplazamiento de los gastos sociales y de las inversiones públicas, y, por ende, una disminución del bienestar de la población; al carecer de las capacidades técnicas y económicas, las fuerzas armadas encuentran dificultades para proveer una genuina defensa externa, de modo que su rol central se desplaza al control de la represión interna y de las fricciones entre civiles y militares causadas por la disminución del bienestar, lo que, en último término, provoca un aumento del gasto militar. Este proceso se da, por lo general, en países menos desarrollados (Scheetz, 1991).

Por otro lado, los autores que han venido sustentando la tesis de que a mayor gasto militar, mayor crecimiento económico, creen que este gasto puede resultar económicamente productivo si lleva a una situación de seguridad nacional y permite ejercer con más eficacia los derechos de propiedad, estimulando así la inversión privada y, por ende, el crecimiento. Han señalado además que el gasto en capital militar puede tener usos productivos: algunos países en desarrollo aún se benefician del transporte y las comunicaciones construidas para propósitos militares.

Así, se ha resaltado que el gasto militar es un rubro capaz de proporcionar alimentación, vivienda, servicios médicos y adiestramiento a un número de personas que, de lo contrario, serían sostenidas por el sector civil; que, como ya se mencionó, puede adelantar una gran gama de trabajos públicos que también benefician a la economía civil, y comprometerse en 
especialidades científicas y técnicas que, de otro modo, recaerían en el personal civil de la sociedad (Benoit, 1973; Thompson, 1974; Frederiksen y Looney, 1982).

Por último, cabe destacar que los estudios individuales acerca de los efectos del gasto militar en el crecimiento económico arrojan resultados aparentemente contradictorios. Sin embargo, Todd Sandler y Keith Hartley concluyen que los modelos basados en la influencia de la demanda generalmente postulan que los gastos militares desplazan la inversión y por lo tanto

\section{III}

\section{Hipótesis}

El estudio del gasto militar es de interés para las diversas disciplinas por sus efectos en los niveles de gasto público y en el crecimiento económico. En tiempos de paz, o por lo menos cuando la supervivencia de valores o instituciones no depende del empleo masivo del aparato militar, se busca que las consideraciones macroeconómicas arbitren la discusión sobre el nivel deseable y posible del gasto militar: es decir, la capacidad fiscal define en última instancia tales controversias.

Sin embargo, hay que explorar las razones por las cuales interesa el análisis de este gasto. Para los economistas, tiene gran importancia por su impacto sobre el crecimiento y las variables macroeconómicas. A quienes toman las decisiones públicas, les resulta fundamental estudiar este gasto por sus efectos sobre las finanzas públicas y por el desplazamiento de recursos que puede causar en otros rubros de gasto del gobierno central. No obstante, pocos se han enfocado en la razón de ser del gasto militar: la capacidad para proveer defensa y seguridad.

Por lo dicho, las discusiones en torno al monto adecuado de gasto militar no son productivas si no se consideran los aspectos microeconómicos. La composición del gasto militar permite inferir su impacto real sobre la producción de la defensa y la seguridad, al tiempo que genera una base más concreta sobre la cual realizar el análisis macroeconómico; asimismo, es fundamental para determinar las tendencias futuras del gasto militar. Si este gasto está predominantemente tienen efectos negativos, mientras que los estudios centrados en la oferta generalmente encuentran efectos positivos o neutros, cualesquiera sean las muestras utilizadas, los períodos analizados o los métodos econométricos empleados. Esto los lleva a concluir que el impacto neto del gasto sobre el crecimiento es levemente negativo y, en consecuencia, que la reducción del gasto militar por sí sola no es un camino deseado para acelerar el crecimiento económico (Sandler y Hartley, 1995, en especial p. 220). compuesto por pagos asociados a la remuneración del personal, las posibilidades de reducirlo disminuyen. Lo contrario ocurre con los gastos de inversión y operación. Vemos así que la probabilidad de variar el gasto militar es inversamente proporcional a los costos de nómina y directamente proporcional a los gastos de operación e inversión.

El estudio de la evolución del gasto militar en Colombia revela que los ciclos de expansión y erosión de éste son producto de programas coyunturales de adquisición de equipos, mientras que los aumentos y reclasificaciones salariales elevan los niveles de gasto y los hacen inflexibles a la baja. Por lo tanto, los programas de ajuste fiscal que afecten al sector militar corren el riesgo de debilitar su capacidad operacional: la discrecionalidad del gasto puede favorecer principalmente a los rubros de inversión y operación, y generar así un desbalance entre el personal y los recursos materiales a su disposición.

En consecuencia, si bien es fundamental analizar el impacto del gasto militar en el crecimiento económico de un país y en las finanzas públicas, tal análisis puede ser insuficiente si no considera la composición interna del gasto. Es esta estructura lo que permite inferir el efecto que el gasto tendrá sobre la economía, la posibilidad de reducirlo y las probabilidades de hacerlo más eficiente, así como también evaluar el efecto que está teniendo sobre la provisión de defensa y seguridad. 


\section{IV}

\section{Gasto en defensa y seguridad}

\section{Comportamiento histórico}

Una revisión del gasto de la Fuerza Pública (GFP) ${ }^{2}$ en Colombia desde 1926 hasta el presente nos revela que la economía ha destinado para su seguridad, en promedio, el $1.8 \%$ del producto interno bruto, con un mínimo de $0.5 \%$ en 1930 y un máximo de $3.6 \%$ en 1997 (gráfico 1). Este rango revela un comportamiento cíclico de expansión y erosión presupuestaria, pero con una tendencia ascendente a lo largo del período. Un análisis más detallado (cuadro 1) nos revela que en los últimos años de la década de 1920 este gasto representaba en promedio el $0.7 \%$ del PIB, nivel que se mantuvo hasta 1932, un año antes que estallara el conflicto limítrofe con el Perú. Este conflicto llevó el GFP a uno de los niveles más altos exhibidos por el país, cercano al 3\%. Luego, en un período de cuatro años,

2 Este gasto corresponde a lo asignado por el gobierno central al Ministerio de Defensa Nacional, e incluye los recursos asignados a las Fuerzas Militares y a la Policía Nacional. Esto implica que no se están teniendo en cuenta los aportes realizados por gobiernos departamentales, distritales o municipales, ni la ayuda de otros países, ni los aportes del sector privado. dicho gasto se redujo a menos del $1.5 \%$ del PIB. Esto demuestra que, si bien el esfuerzo exigido por el conflicto externo fue grande, respondió a factores coyunturales que permitieron desmontarlo con rapidez (gráfico 1 y cuadro 1 ).

En los años cuarenta se dio un hecho sorprendente: mientras se desarrollaba la Segunda Guerra Mundial, en Colombia el nivel de gasto de la Fuerza Pública como porcentaje del PIB estuvo por debajo de su tendencia histórica. Sólo hacia finales de ese decenio e inicios del siguiente se registró un nuevo crecimiento sustancial del GFP, que pasó de menos del $1.1 \%$ del PIB a más del $2.1 \%$. Este período coincidió con importantes acontecimientos de carácter interno, como fueron La Violencia, fenómeno desencadenado por el bipartidismo político, y la Dictadura Militar (19531957) encabezada por el general Gustavo Rojas Pinilla.

No obstante, hacia fines de los cincuenta el crecimiento del GFP había descendido nuevamente a niveles cercanos al promedio. En los años sesenta hubo un incremento moderado. En 1971, con la adquisición de aviones Mirage y fusiles automáticos, se llegó a niveles de GFP superiores al 3\% del PIB, más altos que du-

GRAFICO 1

Colombia: Esfuerzo de la economía en el sector defensa, 1926-1998

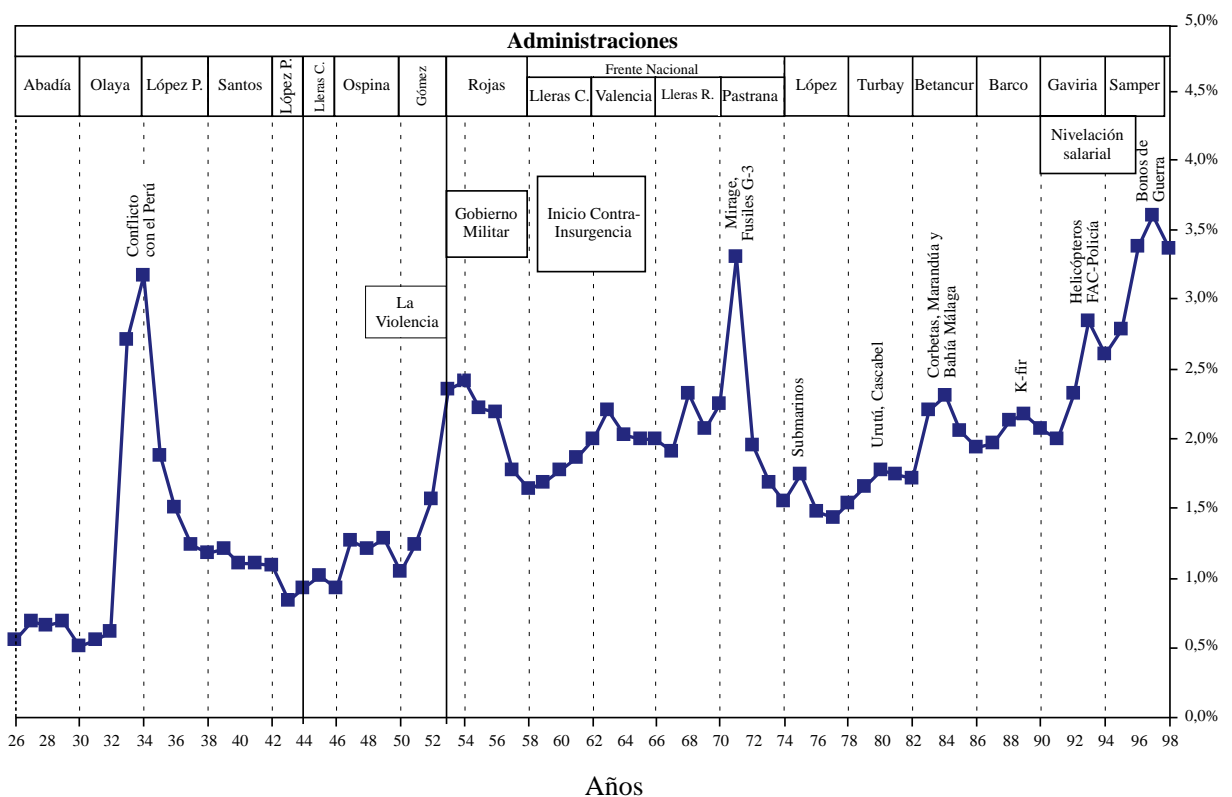


CUADRO 1

Comportamiento del gasto de la Fuerza Pública (GFP) en la economía, 1926-1998

(Por decenios y momentos históricos)

\begin{tabular}{|c|c|c|}
\hline Años & Períodos & $\begin{array}{c}\mathrm{GFP} / \mathrm{PIB} \\
(\%)\end{array}$ \\
\hline \multicolumn{3}{|c|}{ Promedio del período $1926-1998$} \\
\hline 1926-1998 & Período de análisis & 1.8 \\
\hline \multicolumn{3}{|l|}{ Decenios } \\
\hline 1926-1929 & Decenio de 1920 & 0.7 \\
\hline 1930-1939 & Decenio de 1930 & 1.5 \\
\hline 1940-1949 & Decenio de 1940 & 1.1 \\
\hline 1950-1959 & Decenio de 1950 & 1.8 \\
\hline 1960-1969 & Decenio de 1960 & 2.0 \\
\hline 1970-1979 & Decenio de 1970 & 1.9 \\
\hline 1980-1989 & Decenio de 1980 & 2.0 \\
\hline 1990-1998 & Decenio de 1990 & 2.8 \\
\hline \multicolumn{3}{|c|}{ Momentos históricos } \\
\hline 1926-1931 & Preguerra con el Perú & 0.6 \\
\hline 1933-1934 & Guerra con el Perú & 3.0 \\
\hline 1939-1947 & Segunda Guerra Mundial & 1.1 \\
\hline 1948-1952 & La Violencia & 1.3 \\
\hline 1953-1970 & Rojas y el Frente Nacional & 2.0 \\
\hline 1993-1998 & Nivelación salarial & 3.1 \\
\hline
\end{tabular}

Fuente: Contraloría General de la República y cálculos de los autores.

rante el conflicto con el Perú. En seguida, y pese a que en los años setenta se adquirió equipo militar en cantidades relativamente importantes, el promedio de gasto nuevamente descendió a niveles inferiores a la tendencia histórica.

La compra de los vehículos blindados Urutú y Cascabel, la construcción de una base naval en el Pacífico colombiano (Bahía Málaga) y de la pista de la base aérea de Marandúa, ubicada en los llanos orientales del país, así como la adquisición de corbetas misileras en la primera mitad de los ochenta, elevó el gasto, pero sólo a niveles ligeramente superiores al promedio. La adquisición de aviones $K$-fir generó el último aumento de los años ochenta, pero aún así el crecimiento del gasto se situó en un nivel inferior a la tendencia.

Los años noventa marcaron el inicio de un nuevo comportamiento del GFP en el país. En materia de inversión, en 1991 se inició el Plan Quinquenal, que fue complementado con el Plan Energético Vial en sus fases I, II y III. El primero fijó prioridades de inversión, privilegiando los programas de mantenimiento, con el objeto de mejorar el alistamiento y la operatividad de la Fuerza Pública. Por su parte, el Plan Energético Vial, en sus diferentes fases, tenía como finalidad organizar unidades de soldados voluntarios ${ }^{3}$ para proteger los sectores petrolero y eléctrico. Asimismo,

3 Soldados no conscriptos y con remuneración. se pusieron en ejecución los planes Conmoción e Integral en 1992 y 1993, destinados a encarar la ofensiva permanente de los grupos guerrilleros y desarrollar una estrategia de guerra integral como respuesta a las alteraciones de orden público ocasionadas por los diferentes grupos al margen de la ley. Los recursos provistos en estos planes se destinaron al mantenimiento, renovación y complementación de equipo militar faltante, a mejorar la movilidad de las tropas, particularmente mediante helicópteros, y a modernizar las comunicaciones entre los diferentes entes del gobierno, las Fuerzas Militares y la Policía Nacional.

Por el lado de los gastos de funcionamiento, los anteriores programas significaron la activación de un buen número de unidades y la incorporación de un considerable número de efectivos. Además, se dio prioridad a elevar los presupuestos del rubro de gastos generales, especialmente en compra de equipo y materiales y suministros, al fortalecimiento de las actividades de inteligencia, al desarrollo de los servicios de sanidad y al mejoramiento de las raciones de campaña. Finalmente, en materia de servicios personales y transferencias, sueldos y pensiones, se expidió la Ley 4 de 1992, con la cual se realizó una nivelación salarial de los miembros de la Fuerza Pública.

Finalmente, en 1997 la economía hizo su mayor esfuerzo en el sector desde 1926. Dos factores determinaron este hecho: la tendencia estructuralmente creciente de los gastos de funcionamiento, producto de la nivelación salarial de 1992, y los recursos de inversión provenientes de los Bonos para la Seguridad. Estos bonos, también conocidos como bonos de guerra, tenían como objetivo general satisfacer las principales necesidades que afrontaba el sector en el marco de una estrategia contrainsurgente centrada en tres áreas: movilidad, inteligencia y comunicaciones.

La evolución del comportamiento histórico del GFP como porcentaje del PIB en el país permite inferir la evolución de este gasto en el futuro. Cabe resaltar ante todo que a lo largo de este siglo, sin incluir la Guerra de los Mil Días (guerra civil que se desarrolló entre 1899 y 1902), el GFP ha tenido un comportamiento oscilante pero con tendencia ascendente. Sus variaciones pueden explicarse, en gran medida, por factores coyunturales como conflictos o tensiones con países vecinos, determinadas adquisiciones de equipos o de instalaciones de alto costo, o iniciativas para hacer frente a la subversión y el narcotráfico. No obstante, esta dinámica exhibe una ruptura al inicio de los años noventa. La nivelación salarial del personal activo y pasivo de la Fuerza Pública agregó un componente estructural de tendencia creciente al GFP. 


\section{Efectos del gasto de la Fuerza Pública}

Luego de apreciar el comportamiento histórico del GFP en la economía, es de vital importancia establecer sus principales efectos. Un análisis de la serie GFP/PIB muestra una evolución ascendente a lo largo del período 1926-1998 (gráfico 2). Se estima que la Fuerza Pública aumentó su gasto medio anual en $0.023 \%$ del PIB. Es importante señalar que el gasto del gobierno central (GGC) presenta el mismo comportamiento; según cálculos preliminares, su aumento medio anual fue de $0.156 \%$ del PIB. El gasto del gobierno central con otros destinos (GGCOD) ${ }^{4}$, que excluye el sector defensa, creció $0.134 \%$ del PIB.

A primera vista, la diferencia entre las pendientes permitiría asegurar que el sector defensa presenta un sesgo frente al gasto que el gobierno central destina a otros fines. Pero si se comparan las tasas medias de crecimiento anual de estas series, se observa que la anterior afirmación no es cierta. Como proporción del

4 Este gasto también presenta un comportamiento ascendente, aunque más fluctuante, frente, al PIB (5.6\% en 1950 y $20.8 \%$ en 1997).
PIB, el GFP creció $1.532 \%$ mientras que el GGC y el GGCOD crecieron $1.250 \%$ y $1.245 \%$, respectivamente (cuadro 2 y gráfico 3 ).

Tal comportamiento se explica porque el gobierno central destinó, en promedio, más recursos al sector defensa que al resto de los sectores. La tasa de

CUADRO 2

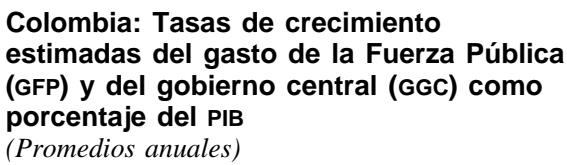

Colombia: Tasas de crecimiento estimadas del gasto de la Fuerza Pública (GFP) y del gobierno central (GGC) como porcentaje del PIB (Promedios anuales)

\begin{tabular}{|c|c|c|c|}
\hline & 1926-1998 & 1926-1979 & 1980-1998 \\
\hline GFP/PIB & 1.532 & 1.777 & 3.531 \\
\hline GGC/PIB & 1.250 & 0.761 & 3.824 \\
\hline GGCOD/PIB $^{\mathrm{a}}$ & 1.245 & 0.642 & 3.873 \\
\hline GFP/GGC & 0.284 & 1.016 & -0.294 \\
\hline GGCOD/GGC & -0.003 & -0.119 & 0.049 \\
\hline
\end{tabular}

Fuente: Contraloría General de la República y cálculos de los autores.

a GGCOD = gasto del gobierno central con otros destinos (excluye el GFP).

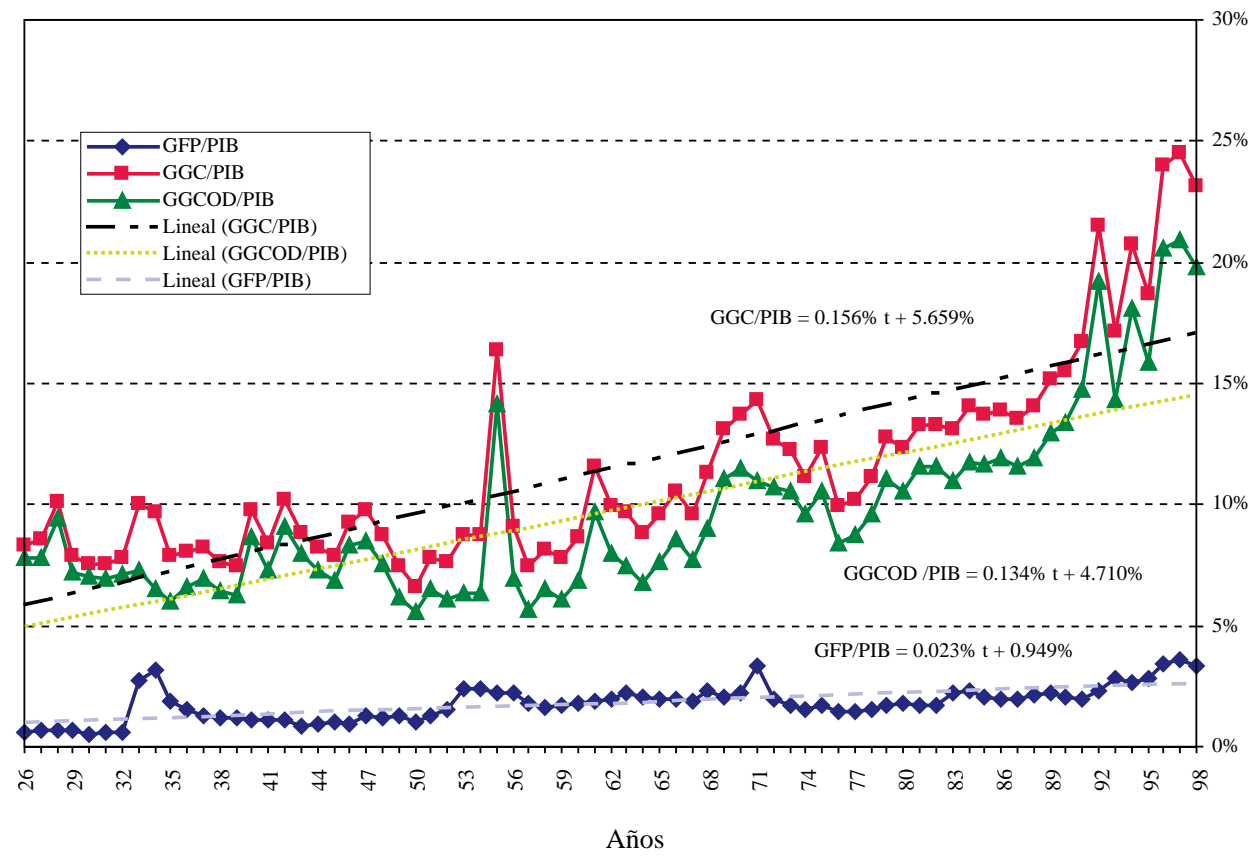

a GFP = Gasto de la Fuerza Pública; GGC = Gasto del gobierno central; GGCOD = Gasto del gobierno central con otros destinos. 
GRAFICO 3

Colombia: Sector defensa y gobierno central con otros destinos en la economía, 1926-1998 ${ }^{a}$

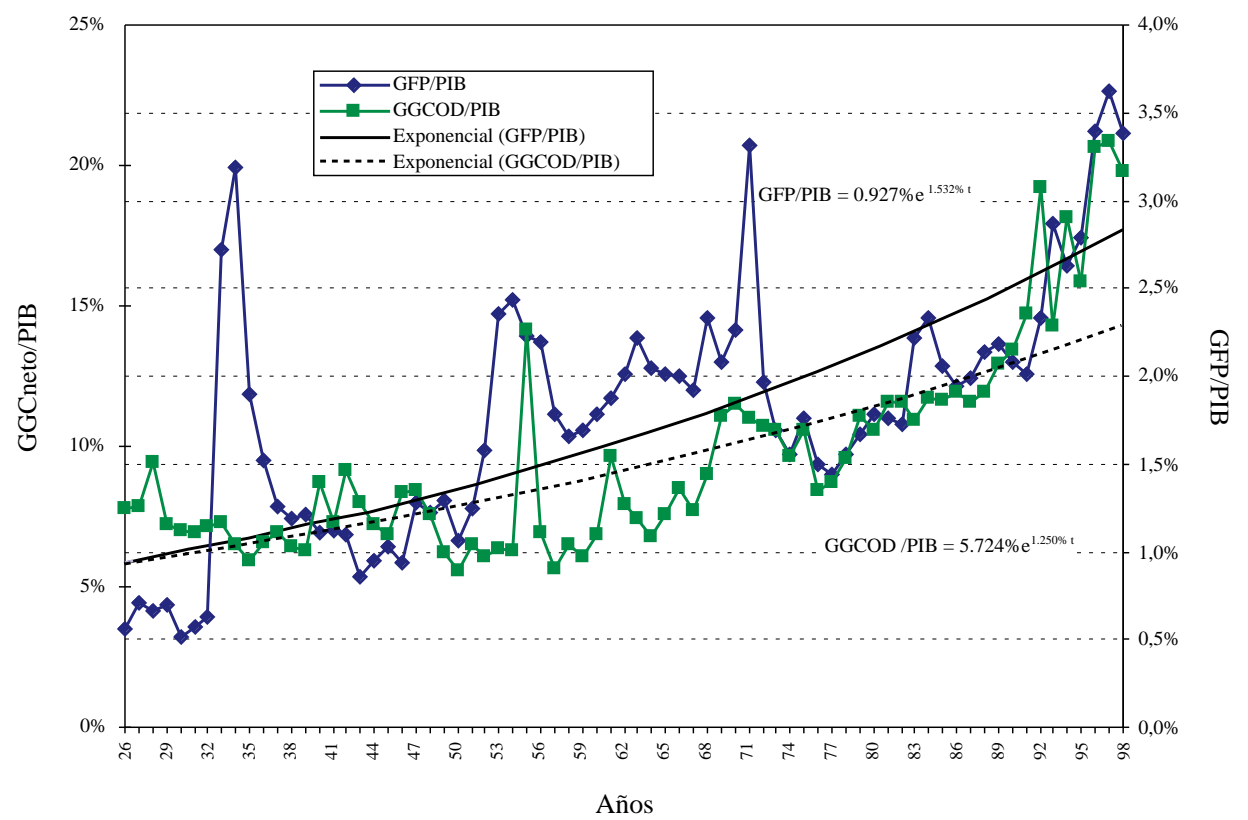

a GFP $=$ Gasto de la Fuerza Pública

GGCOD $=$ Gasto del gobierno central con otros destinos

crecimiento media del GFP en el gasto del gobierno central fue de $0.284 \%$ y la del GGCOD fue de $-0.003 \% 5$ (gráfico 4).

Por el comportamiento de la relación GFP/GGC se puede inferir que el sector defensa es una restricción para el GGC, pues, según se observa, cuando se otorgaron recursos adicionales a otros sectores no militares, el GFP también aumentó su participación en el gasto del gobierno central. Esto explicaría la participación creciente del GGC en el PIB. ${ }^{6}$

Si el gobierno central hubiera mantenido constante su participación en el PIB (por ejemplo, en 11.26\%), en 1998 el GGCOD hubiera equivalido al 7.8\% del PIB (y no al $20.9 \%){ }^{7}$ pero como el gobierno central ha venido comprometiéndose con mayores responsabilidades, ha tenido que apropiarse de mayores recursos de la economía.

\footnotetext{
5 Pruebas de causalidad demuestran que el GGCOD/GGC causa (en forma inversa) al GFP/PIB.

6 O por el contrario, el sector defensa sería garante del nuevo gasto.

7 Mientras las series GFP/GGC, GFP/PIB y GGCOD/GGC son estacionarias, es decir, varían en torno a la media (tienden a autocorregirse), las relaciones GGC/PIB y GGCOD/PIB tienen raíz unitaria (son paseos aleatorios y sus varianzas tienden a infinito, dificultando su modelaje).
}

¿Qué relación de causalidad existe entre GFP/PIB y GGCOD/PIB? Pruebas de causalidad en el sentido de Granger demuestran que GGCOD/PIB causa a GFP/PIB en forma directa (GGCOD/PIB es no estacionario y con tendencia creciente). Además, GGCOD/GGC (con tendencia negativa) causa en relación inversa a GFP/PIB. Sin embargo, no existe relación de causalidad entre GGCOD/PIB y GGCOD/GGC. ${ }^{8}$

Por otra parte, al analizar por decenios la participación media de una y otra de estas dos variables se observa un efecto de sustitución. ${ }^{9}$ Ejemplo de ello son los decenios de 1930, 1950 y 1970 (cuadro 3). En los años sesenta a noventa se presenta un efecto de complemento, es decir, ambas crecen pero a diferentes tasas que afectan sus participaciones en el gasto del gobierno central. Esto sólo puede suceder si el gobierno central se apropia de mayores recursos del PIB.

\footnotetext{
8 Este análisis no se cumple para el subperíodo 1980-1998 ya que la tendencia de GGCOD/GGC cambia a creciente (manteniendo la relación indirecta) y, por tanto, el gasto de la Fuerza Pública debería disminuir su participación en el PIB.

9 Efecto de sustitución: relación inversa entre las variables.
} 


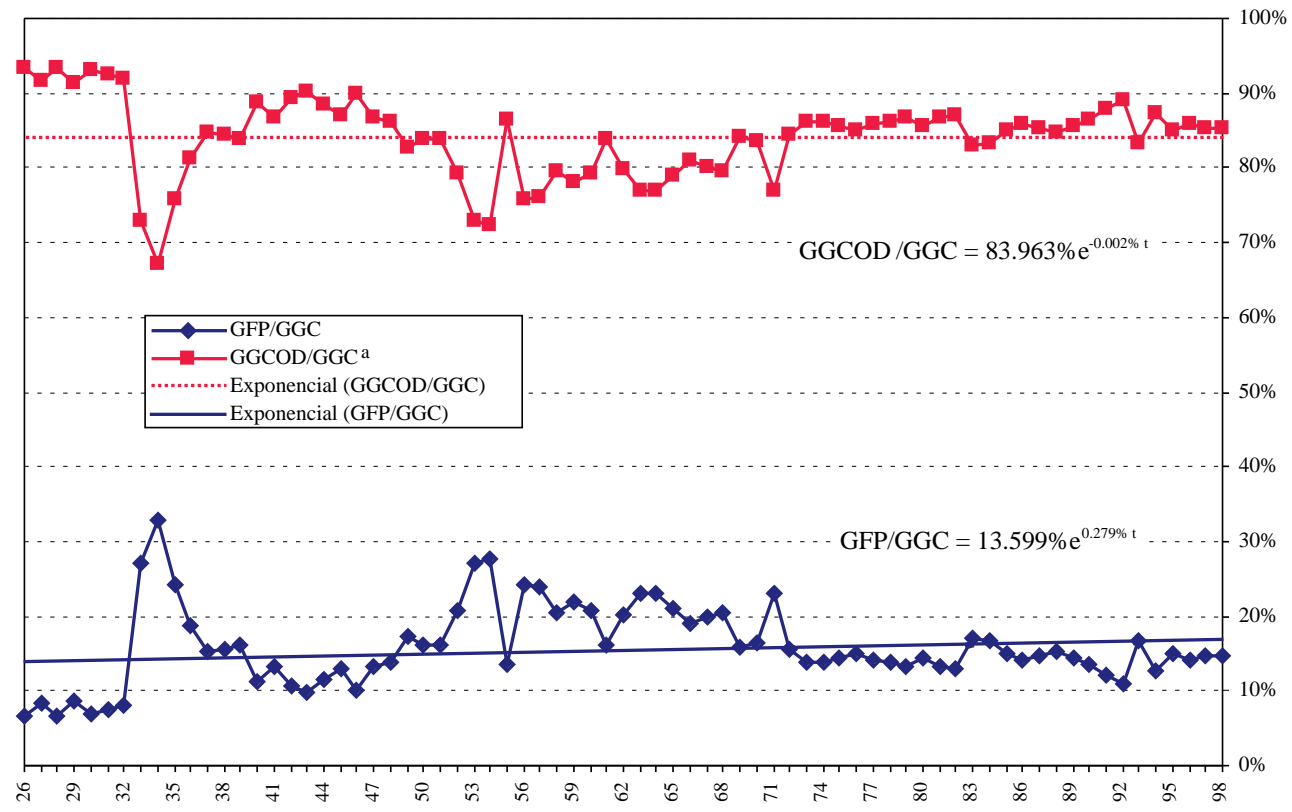

Años

a GGCOD = Gasto del gobierno central con otros destinos.

CUADRO 3

Colombia: Comportamiento de las series de gasto del gobierno central (GGC), de la Fuerza Pública (GFP) y con otros destinos (GGCOD) por decenios (Porcentajes)

\begin{tabular}{|c|c|c|c|c|c|c|c|c|}
\hline Decenios & GFP/GGC & Var. \% & GFP/PIB & Var. \% & GGC/PIB & Var \% & GGCOD/PIB ${ }^{\mathrm{a}}$ & Var \% \\
\hline De $1920^{b}$ & 7.6 & & 0.7 & & 8.7 & & 8.1 & \\
\hline De 1930 & 17.3 & 127.5 & 1.5 & 124.2 & 8.2 & -6.2 & 6.7 & -16.8 \\
\hline De 1940 & 12.4 & -28.0 & 1.1 & -25.9 & 8.9 & 8.3 & 7.8 & 15.8 \\
\hline De 1950 & 21.1 & 70.1 & 1.8 & 67.4 & 8.8 & -0.2 & 7.0 & -9.7 \\
\hline De 1960 & 20.0 & -5.6 & 2.0 & 11.1 & 10.3 & 16.3 & 8.3 & 17.7 \\
\hline De 1970 & 15.3 & -23.1 & 1.9 & -7.7 & 12.0 & 17.1 & 10.2 & 23.2 \\
\hline De 1980 & 14.7 & -3.9 & 2.0 & 7.7 & 13.6 & 13.3 & 11.6 & 14.4 \\
\hline De $1990^{c}$ & 13.8 & -6.5 & 2.8 & 38.5 & 20.2 & 48.2 & 17.4 & 49.9 \\
\hline
\end{tabular}

Fuente: Contraloría General de la República y cálculos de los autores.

a GGCOD = gastos del gobiernos central con otros destinos (excluye defensa). $\quad$ b 1926 a $1929 . \quad$ c 1990 a 1998.

a) Composición actual del gasto

En el período 1980-1998, el principal componente del GFP fue el rubro servicios personales constituido por la remuneración a la planta de personal, que representa el $45.2 \%$ del gasto. El rubro transferencias constituye el $26.2 \%$ y se destina básicamente a pagos por concepto de seguridad social, pensiones ${ }^{10} \mathrm{y}$ auxilio de cesantía. El rubro gastos generales representa el 14.8\%, tiene como finalidad la adquisición de bienes y servi-

\footnotetext{
${ }^{10}$ Asignaciones al personal en retiro.
} 
CUADRO 4

Colombia: Composición del

gasto de la Fuerza Pública

(Porcentajes)

\begin{tabular}{lccc}
\hline Período & $\begin{array}{c}\text { Remuneración del personal } \\
\text { activo y en retiro }\end{array}$ & Operación & Inversión \\
\hline $1980-1998$ & 71.4 & 14.8 & 13.8 \\
$1980-1992$ & 70.0 & 13.8 & 16.4 \\
$1993-1998$ & 72.9 & 15.8 & 11.3 \\
\hline
\end{tabular}

Fuente: Contraloría General de la República y cálculo de los autores.

cios destinados a garantizar la operación del sector, ${ }^{11}$ y constituye el $13.8 \%{ }^{12}$ del gasto. Así, se observa que la remuneración del personal activo y retirado (servicios personales y transferencias) representa el $71.4 \%$ del gasto (cuadro 4). El incremento del rubro servicios personales refleja el aumento del número de efectivos. Este último creció, en promedio, $4.2 \%$ anual entre 1980 y 1998, mientras que la población lo hizo en $2.0 \%$, lo que significa que un porcentaje mayor de la población forma parte de la fuerza pública (435 soldados por cada 100 mil habitantes en 1980 y 641 en 1998).

Además en 1992, con la nivelación salarial y las provisiones para el pago de auxilios de cesantía, el gasto en servicios personales y en transferencias aumentó considerablemente. Esto se tradujo en una recomposición del GFP, siendo la inversión la variable más afectada. ${ }^{13}$

Lo anterior se reflejó en un incremento de recursos para el sector (gráfico 5) que tras haber sido de 2.1\% del PIB en 1980-1992 fue de 3.1\% en 1993-1998 (3.6\% en 1997). Antes de la nivelación salarial se destinaba el $1.4 \%$ del PIB a remunerar al personal activo y retirado, $0.3 \%$ a operaciones de la Fuerza Pública y $0.3 \%$ a compra y mantenimiento del equipo ( $2.1 \%$ en total). En el período 1993-1998 estos valores pasaron a $2.3,0.5$ y $0.4 \%$, respectivamente $(3.2 \%$ en total). ${ }^{14}$

\footnotetext{
${ }^{11}$ En la actualidad en el país se discute si esta inversión incrementa la formación bruta de capital en la economía. En este trabajo se considera que la mezcla del factor equipo militar (armas, aviones, hospitales de campaña y otros) y del factor humano genera el producto que satisface las demandas de defensa y seguridad de la sociedad.

${ }^{12}$ El rubro inversión tiene un peso similar al de gastos generales en la mayoría de los años.

${ }^{13}$ En 1997, los recursos otorgados a este sector por los bonos de guerra equivalieron al $1.45 \%$ del presupuesto ordinario para ese año.

${ }^{14}$ Aunque se destinen mayores recursos al sector, los rubros gastos generales e inversión han fluctuado (cada uno) entre $0.2 \%$ y $0.5 \%$ del PIB.
}

En 1997 se destinó a la Fuerza Pública el 3.6\% del PIB y se distribuyó así: $2.4 \%$ del PIB para remuneración de los efectivos, $0.5 \%$ para operaciones y $0.7 \%$ para inversión. Se prevé que en el futuro este sector se apropiaría de mayores recursos de la economía, que fluctuarían entre $4.1 \%$ y $5.3 \%$ del PIB $^{15}$ en el $2005^{16}$ (gráfico 6).

\section{b) Restricción fiscal del gobierno central}

Con la descentralización administrativa de 1991 se esperaba que el gobierno central se liberara de responsabilidades directas, con lo cual disminuiría su nivel de gasto. Sin embargo, contrariamente a lo esperado, los nuevos compromisos que le adjudicó la Constitución de 1991 hicieron que la participación del gasto del gobierno central en el PIB aumentara considerablemente, hasta alcanzar el $24.5 \%$ en 1997 (o el $17.9 \%$ si se excluye el servicio de la deuda). Este incremento no es recomendable para la economía y es necesario reducirlo a corto plazo. ${ }^{17}$

Si el sector defensa no modifica su comportamiento (gráfico 7), a poco andar el gobierno central deberá destinarle cada año una proporción mayor de su gasto (hasta un $17.2 \%$ en el 2002).$^{18}$ Esto implica que la economía sólo podrá destinar como máximo un 3.5\% del PIB ${ }^{19}$ (gráfico 8 ). Entre este comportamiento y la proyección del GFP se presenta un déficit creciente calculado de $0 \%$ a $0.1 \%$ del PIB (1999), $0.1 \%$ a $0.3 \%$ (año $2000), 0.2 \%$ a $0.6 \%$ (2001) y $0.4 \%$ a $0.8 \%$ (2002).

Desde el punto de vista econométrico existe evidencia de causalidad del PIB al GFP. Además, los modelos de largo plazo reflejan una relación directa, aunque esta causalidad no se cumple de manera inversa. De estos resultados se puede deducir lo siguiente: el GFP no genera un crecimiento en el PIB, pero tampoco se podría afirmar que una reducción del GFP conlleve un aumento del PIB.

\footnotetext{
15 Se aplicaron dos modelos econométricos donde el PIB (rezagado en uno y cuatro años) es la variable explicativa.

${ }^{16}$ Haciendo un análisis basado en una serie de largo plazo, el rango se amplía a $6.7 \%$ y $6.8 \%$ del PIB.

${ }^{17}$ Para el siguiente análisis se supuso que el nivel de GGC disminuiría 4 puntos porcentuales del PIB en los próximos tres años.

${ }^{18}$ La proyección del GFP se efectuó mediante la aplicación del modelo de mecanismo de corrección de errores a las diferencias entre los logaritmos de las variables y el coeficiente de ajuste de la ecuación de cointegración (Véase el anexo estadístico y econométrico).

${ }^{19}$ Vale la pena aclarar que este nivel de gasto frente al PIB no se puede mantener en el tiempo porque implicaría disminuir permanentemente la participación del gasto del gobierno central en la economía, hasta llegar un momento en que este último se destinaría sólo al sector defensa.
} 
GRAFICO 5

Colombia: Participación del gasto de la Fuerza Pública (GFP) en el PIB, 1980-1998

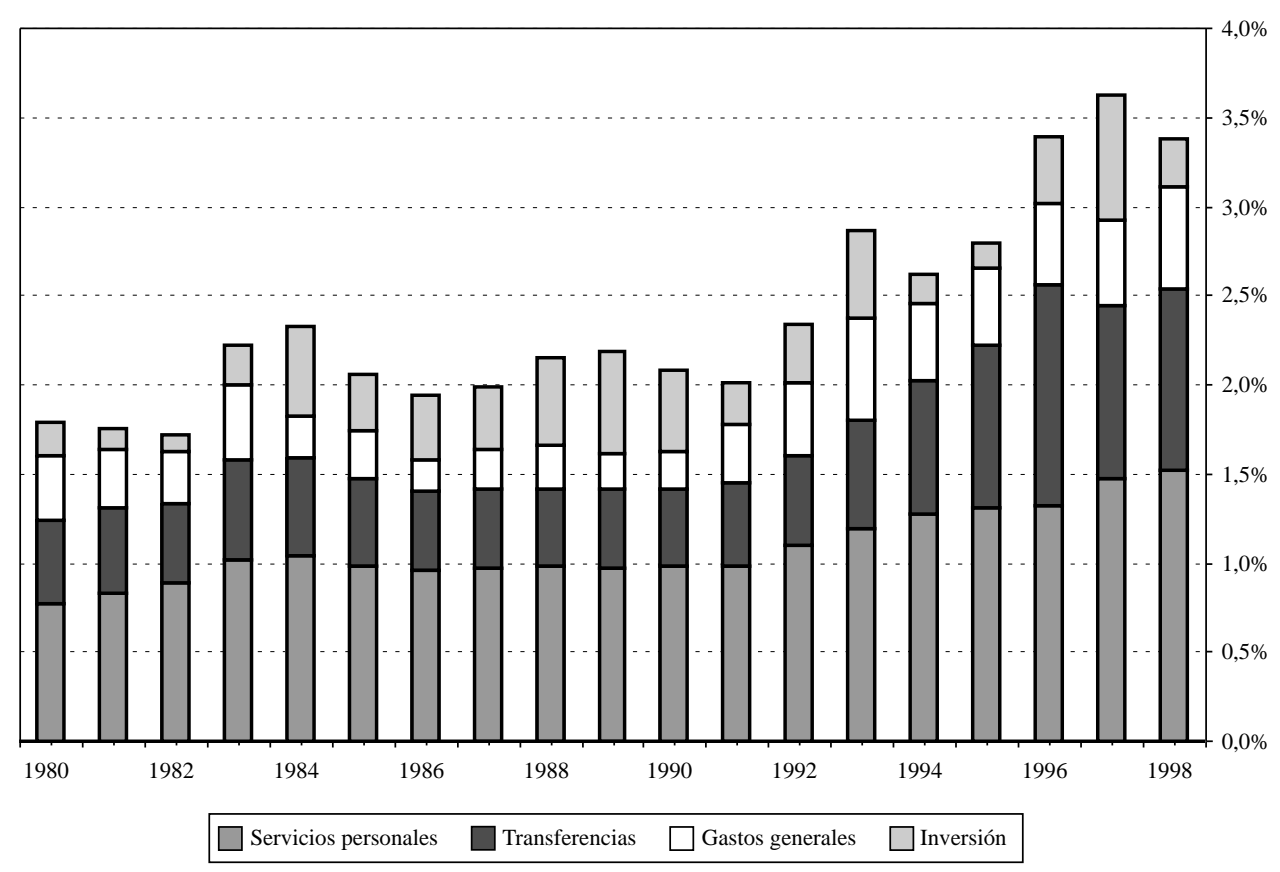

GRAFICO 6

Colombia: Evolución y proyección del gasto de la

Fuerza Pública (GFP) como proporción del PIB 1980-2004

(Análisis de corto plazo)

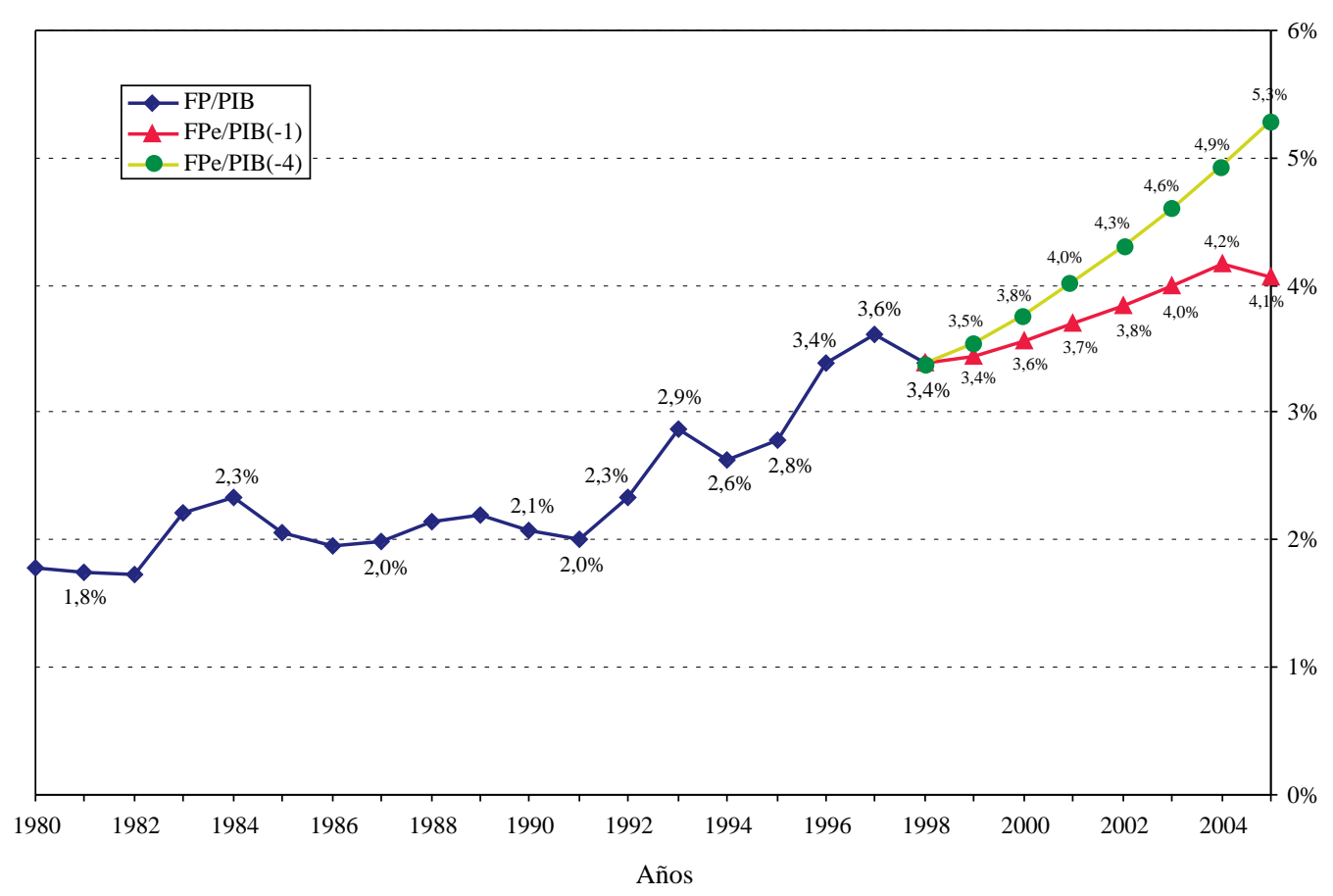



frente a un recorte del GGC como proporción del PIB, 1980-2002

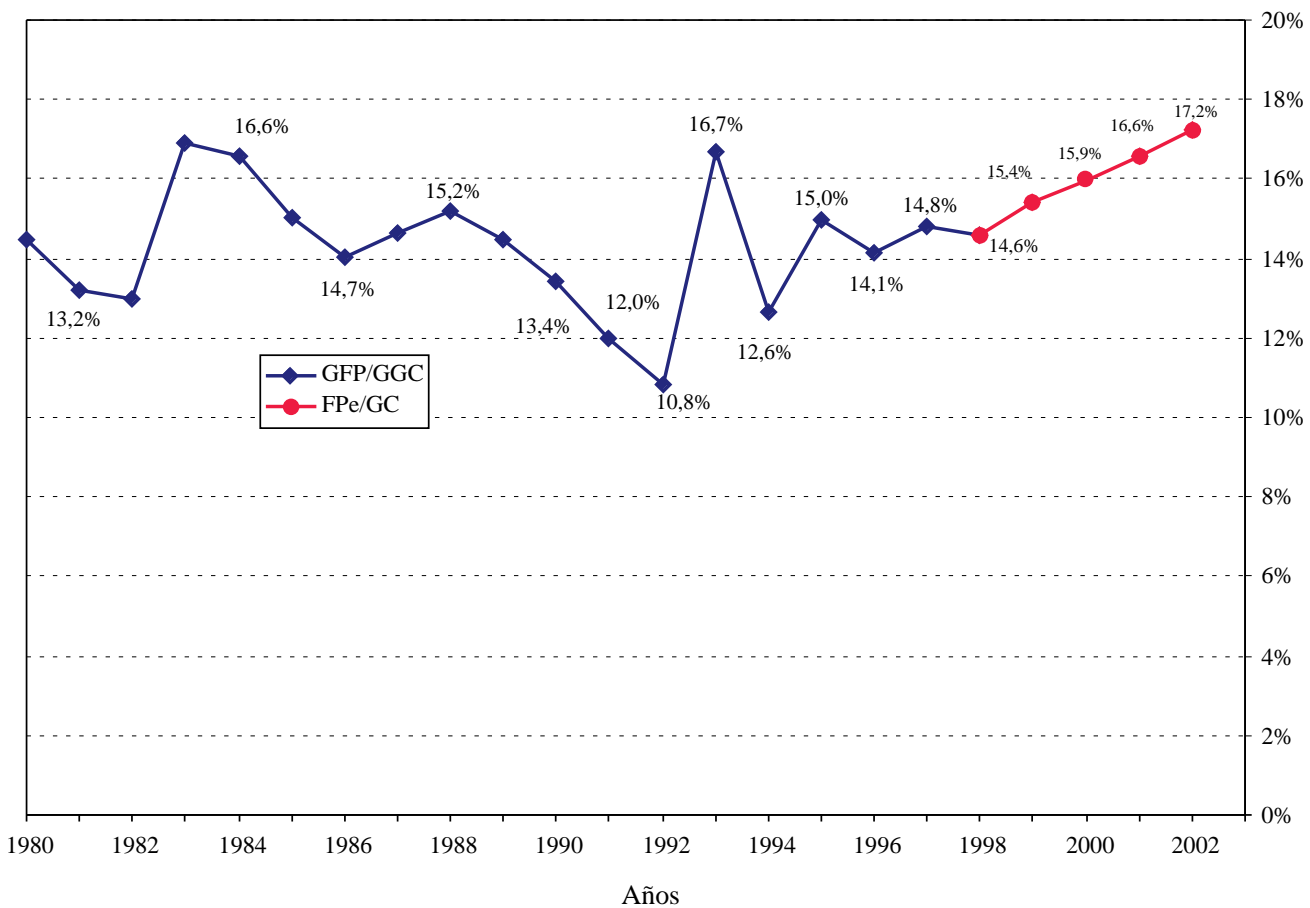
en el gasto del gobierno central, 1980-2005

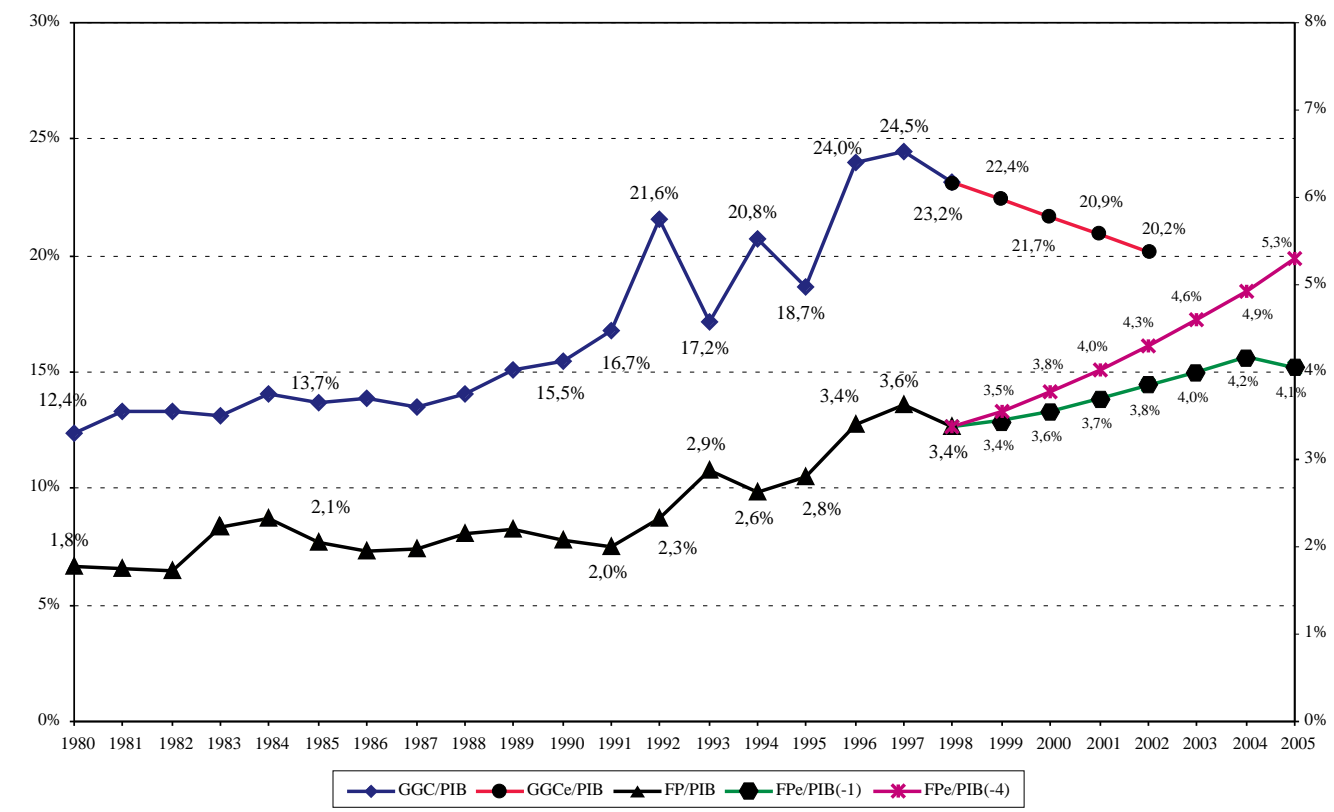


Como se mencionó anteriormente, los factores históricos determinantes del crecimiento del GFP han sido la compra de equipo e instalaciones, es decir, las variables de ajuste del presupuesto de la Fuerza Pública han sido los rubros inversión y gastos generales. De igual forma se puede apreciar que si bien ha habido un aumento del porcentaje del PIB dedicado al GFP, estos rubros se han mantenido en rangos relativamente estrechos. Por lo tanto, si se combina una participación creciente del gasto de nómina con un crecimiento menos que proporcional del gasto total, el espacio para la inversión puede hacerse cada vez más restringido en el futuro.
En consecuencia, si se fija un tope al GFP como proporción del PIB, la dinámica interna del gasto haría que los gastos de nómina desplazaran la participación de la inversión y la constante participación de los gastos generales en el PIB.

Los resultados anteriores ponen de relieve la necesidad de llevar adelante reformas de fondo en el sector defensa con el fin de ayudar a reducir el gasto del gobierno central. Teniendo en cuenta que cada año se incorpora más población al sector, lo que de hecho demanda más recursos, si se continúa con la tendencia actual el porcentaje del PIB destinado a la Fuerza Pública sólo alcanzará para el pago de su personal activo y en retiro.

\section{Eficiencia del gasto militar}

$\mathrm{Al}$ analizar la composición interna del GFP en Colombia es posible establecer que la actual estructura de la Fuerza Pública debe ser revisada debido a consideraciones de eficiencia. Los planes y programas desarrollados en el pasado por lo general buscaban tener más de lo mismo. Esto ha repercutido a nivel macroeconómico porque se ha carecido de una política de gasto que permita mantener el GFP dentro de límites fiscalmente sostenibles.

No obstante, más que ahondar en el impacto que el gasto militar pueda tener sobre la economía, es de vital importancia profundizar en la estructura de costos actuales del aparato de defensa y seguridad del país. Como se indicó anteriormente, los recursos monetarios asignados al sector no se traducen necesariamente en más capacidad para proveer seguridad. Aunque el sector representa una carga presupuestaria bastante alta para el Estado, sus funciones se estarían viendo limitadas por su propia estructura interna. Así, para entender la dinámica sectorial y sus repercusiones en el ámbito macroeconómico, es fundamental el análisis microeconómico del GFP.

Por lo anterior, es recomendable iniciar la reducción de costos introduciendo cambios en las áreas de manejo de personal y de administración de recursos físicos. Ante todo, es preciso examinar el sector defensa y seguridad, considerando dos aspectos fundamentales para decidir líneas de acción. El primero, de carácter organizacional, es la relación entre personal operativo, por un lado, y personal administrativo y de apoyo, por otro. El segundo, de implementación, es la forma en que se aplica la acción de la Fuerza Pública. Ambos aspectos enmarcan el fortalecimiento de esta fuerza en un contexto de restricción fiscal.

La relación combate/apoyo representa el número de hombres requeridos para sostener a un solo soldado en un área de combate. Digamos que en Colombia, hoy, por cada soldado en combate hay aproximadamente ocho de apoyo. Si se modificara apreciablemente esta relación la labor de la Fuerza Pública sería más eficiente. Los parámetros internacionales establecen que tal relación debería estar en torno del 1:3. Una estructura más ligera, más ágil en su movilización, permitiría incrementar la capacidad de combate.

De allí que la estructura del sector debe ser reevaluada. Las decisiones que se adopten para disminuir personal administrativo (a una relación combateapoyo de 1:3, por ejemplo) pueden ser de dos tipos, no necesariamente excluyentes. De una parte, se puede optar por una política de reducción del número de efectivos, que conlleva la disminución de componentes administrativo en las unidades y la modificación de la relación oficial/soldados. Esta opción puede bajar los costos directos asociados a las Fuerzas Militares, pero no significa necesariamente una mayor capacidad de combate; además, supone mayores costos indirectos, porque se traduciría en el retiro anticipado de personal con derecho a pensión, y habría que establecer incentivos para retiros voluntarios o, por lo menos, algunos mecanismos viables de vinculación al mercado laboral o educativo. 
De otra parte, puede optarse por una reorganización al interior de la Fuerza Pública. Esto permitiría duplicar, por lo menos, la capacidad de combate con el mismo personal. Se generaría así una estructura más eficiente y una disminución de la tasa de crecimiento del número de efectivos, por lo menos en el mediano plazo, lo que es más compatible con las restricciones fiscales de tipo macroeconómico ya expuestas.

Consideraremos ahora la relación ataque/defensa, que establece la relación entre las fuerzas atacantes y las fuerzas defensivas. Algunas de las principales señales que recibe la opinión pública colombiana sobre la situación en materia de orden público son los ataques de la guerrilla a puestos militares aislados, las emboscadas a sus patrullas y la toma de poblaciones. Estas acciones sintetizan la interacción militar de la Fuerza Pública y la guerrilla. Por lo tanto, este tipo de contactos armados puede ser la unidad de análisis que permita formarse una visión realista de la confrontación entre las fuerzas regulares y la subversión.

Si se comparan las cifras agregadas de efectivos de la subversión y de la Fuerza Pública, la relación de fuerzas favorece a esta última. No obstante, tal relación de fuerzas no es útil para un análisis objetivo, pues los combates nunca se dan entre el total de la Fuerza Pública y el total de la guerrilla. La guerra de guerrilla consiste precisamente en evitar una confrontación de esa índole. Por lo tanto, la relación de fuerzas debe establecerse en el contexto de los combates aislados, preferidos por la subversión. En ellos, por lo que se ha observado, la guerrilla suele contar con un potencial mayor que el de la Fuerza Pública para tener éxito, lo que pone de relieve la ineficacia de la política de mantener una presencia dispersa de la Fuerza Pú-

\section{VI}

\section{Conclusiones}

El análisis de la dinámica del gasto militar en Colombia nos demuestra que si bien el Estado ha gastado comparativamente pocos recursos en su defensa a lo largo del siglo XX, en los años noventa este gasto ha aumentado significativamente. Y si consideramos los principios que justifican este gasto, es evidente que la Fuerza Pública colombiana no está logrando sus objetivos en materia de seguridad interna.

El Estado colombiano enfrenta la necesidad de mejorar la eficiencia de la Fuerza Pública para proveer blica en zonas de conflicto. Más que hacer presencia, la Fuerza Pública debe concentrar sus esfuerzos en prepararse para tener en esas zonas aisladas un potencial superior al de los grupos armados ilegales, ya sea siendo más eficaz en la defensa o logrando una estructura adecuada para el ataque. La decisión en uno u otro sentido deberá depender de la región en que se esté operando, del apoyo que ofrezca la comunidad y de las organizaciones armadas al margen de la ley que se encuentren en dichas zonas.

Para mejorar la relación cambate/apoyo y modificar la relación defensa/ataque, como queda claro, no es necesario aumentar el número de efectivos, sino reorganizar los existentes. Esta propuesta implica decisiones en dos frentes: cambiar la actual estructura de la Fuerza Pública para que haya más personal combatiendo, y modificar la actual relación ataque/defensa para establecer puntos fuertes, ya sea como fuerza defensiva o como fuerza ofensiva. La experiencia pasada nos ha demostrado que la necesidad política de que la Fuerza Pública haga presencia en todo el territorio ha sido militarmente ineficiente y económicamente insostenible.

La reestructuración del personal es una condición suficiente para disminuir la presión del sector sobre los recursos fiscales (eficiencia) y una condición necesaria para mejorar los resultados en el campo militar (eficacia). No obstante, no se logrará mejorar los resultados si no se replantea la dotación de equipo. No se trata de adquirir más de lo mismo, sino de dotar al personal de equipos idóneos para contrarrestar el tipo de combate actual. Y esta mejor dotación de equipos se debe dar tanto en la parte operativa como en la de apoyo, ya que si esto no se hace, se dificultará el traslado de personal de apoyo a combate.

seguridad a los ciudadanos, y a la vez, reducir su estructura de costos. Estos objetivos parecen ser contrapuestos, pero es política y militarmente imperioso que la Fuerza Pública retome el monopolio de las armas, y es económicamente indispensable que lo haga con una estructura de costos más racional. De no ser así, el GFP resultaría verdaderamente improductivo, pues continuaría el deterioro de las instituciones democráticas del país y se generaría un serio desequilibrio en las finanzas del Estado. 
En este artículo se sostiene que no es suficiente analizar el impacto macroeconómico del gasto que una determinada sociedad realiza en defensa y seguridad. Es indispensable ir más allá y conocer a fondo la composición de este rubro, con el fin de contar con una base real sobre la cual realizar el análisis tanto microeconómico como macroeconómico. La composición actual de este gasto en Colombia lleva a pensar en las dificultades que existen para reducirlo.

Puede argumentarse que de poco serviría tener las finanzas públicas en orden si la sociedad no está igualmente en orden. En Colombia, con el actual régimen de gasto de la Fuerza Pública, es poco probable la consolidación de la legitimidad del Estado y sí muy probable el deterioro de las finanzas públicas. La proyección del gasto de la Fuerza Pública en el futuro inmediato revela una dinámica explosiva que lo situaría en niveles superiores al 5\% del producto interno bruto hacia el año 2005.

Tales resultados son incompatibles con el reajuste de las finanzas públicas requerido, que exige una reducción radical del gasto del gobierno central en el corto plazo. La estructura de gasto actual es incompatible con una política fiscal sana. No obstante, la fijación de un tope al porcentaje del PIB destinado a la Fuerza Pública no representa una solución eficiente al incremento del GFP si no se reforma la dinámica interna de éste; como se ha visto, la tendencia ascendente de este gasto, por factores asociados a la nómina, desplazaría la inversión y los gastos de operación al punto que sólo se podrían pagar sueldos y pensiones. Lo que sí puede generar ahorros en el presupuesto del Ministerio de Defensa Nacional son las reformas en las áreas siguientes: i) dinámica presupuestaria y proceso de adquisiciones, y ii) manejo de personal e instalaciones físicas.

Los ahorros más significativos del sector defensa necesariamente están asociados con el manejo del personal. El $73 \%$ de los recursos de defensa y seguridad se destinan a gastos de nómina. Por lo tanto, es preciso iniciar la revisión del sistema general de manejo de personal. Al respecto pueden considerarse medidas como i) la modificación del régimen de prestaciones; ii) el aumento de la edad de retiro; iii) la disminución del número de efectivos, y iv) el cambio de la relación fuerzas de combate/personal de apoyo y administrativo.

La modificación del sistema de prestaciones es la recomendación más radical, pues implicaría incorporar el personal del Ministerio de Defensa Nacional al régimen general de seguridad social. Aun siendo la solución más directa al problema estructural, es también la más improbable debido a sus inherentes dificultades políticas. La reducción del personal en servicio a través de programas de retiro anticipado es la opción más viable. Además, es imperativo mejorar la relación personal de combate/personal de apoyo y administrativo, ya que ésta es la manera más fácil de aumentar el poder de combate con la actual nómina.

Para resolver los problemas de personal habrá que adoptar decisiones de gran trascendencia, cada una de las cuales tendrá profundas repercusiones políticas, militares, económicas y sociales. La adopción de cualquiera de ellas dependerá, en gran medida, de consideraciones tan amplias como el estado de la economía, el clima político, la opinión pública o el entorno de seguridad predominante. No obstante, estos problemas deben ser abordados y resueltos con claridad, en aras de la seguridad y el bienestar económico del país.

El problema derivado del conflicto interno del país no se resuelve reduciendo el presupuesto del Ministerio de Defensa Nacional. Es un hecho que el gasto militar continuará existiendo y la seguridad interna y la defensa externa seguirán necesitando recursos que deberán proveerse. El país está invirtiendo en ello, así como se invierte en una póliza de seguro. Por lo tanto, la cobertura debe concretarse y ser lo más amplia posible.

En este artículo hemos señalado que, debido a la estructura de costos actuales del aparato de seguridad y defensa del país, el aumento de los recursos monetarios destinados a él no se traduce necesariamente en una mayor capacidad para suministrar seguridad. Hay muchas áreas en que es posible explorar formas de multiplicar el efecto de cada peso invertido en la seguridad nacional. No obstante, para hacer frente al conflicto es tan necesaria una fuerte voluntad política y societal como la disponibilidad de recursos materiales y financieros. 


\section{Anexo. Resultados estadísticos y econométricos}

GRAFICO A1

Colombia: Peso de la Fuerza Pública en la población y en el PIB, 1950-1998a

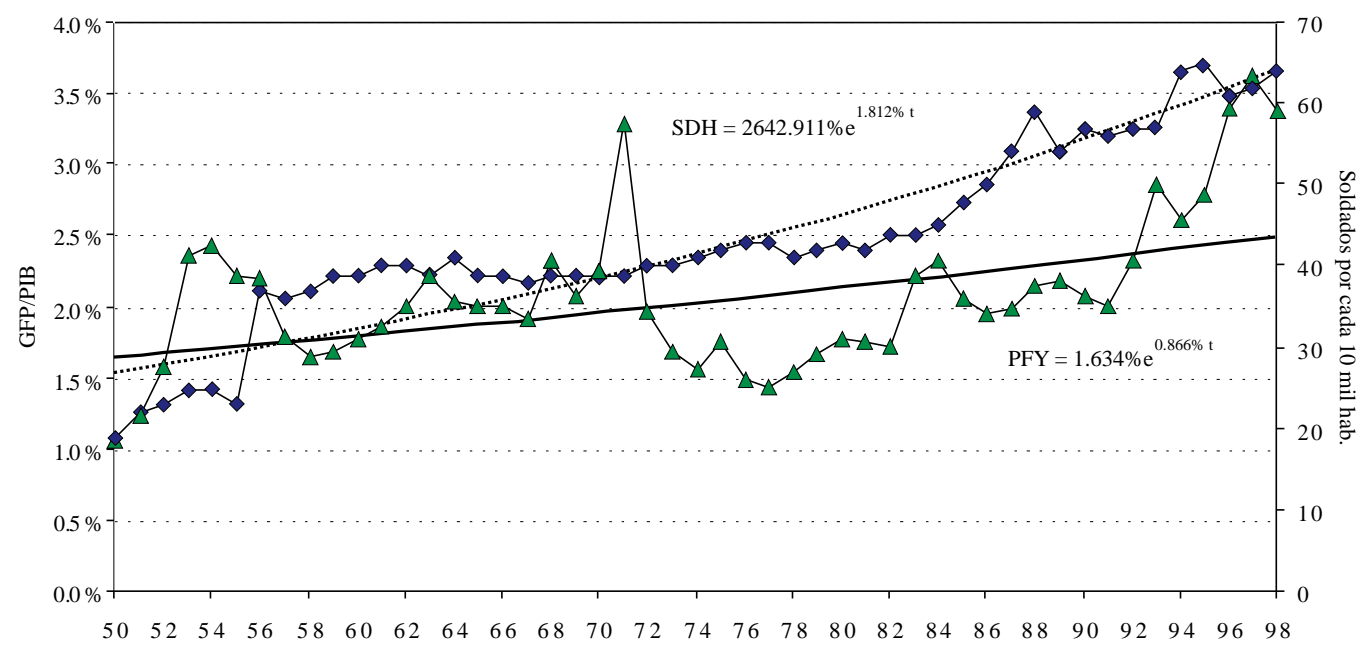

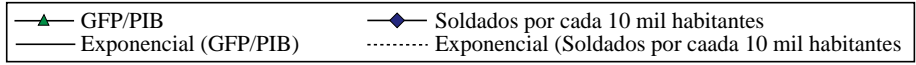

Fuente: Contraloría General de la República de Colombia.

a $\quad$ FPY = Gasto de la fuerza pública como proporción del PIB (GPF/PIB).

$\mathrm{SDH}=$ Soldados por cada 10 mil habitantes.

CUADRO A1

Colombia: Composición del gasto de la Fuerza Pública (Porcentajes)

\begin{tabular}{lccc}
\hline & Remuneración Operación & Inversión \\
\hline 1980 & 69.1 & 20.7 & 10.2 \\
1981 & 74.4 & 19.1 & 6.5 \\
1982 & 77.3 & 16.9 & 5.7 \\
1983 & 71.0 & 19.3 & 9.7 \\
1984 & 68.3 & 10.3 & 21.4 \\
1985 & 71.7 & 12.7 & 15.5 \\
1986 & 72.3 & 9.0 & 18.6 \\
1987 & 71.5 & 11.0 & 17.5 \\
1988 & 65.9 & 11.5 & 22.6 \\
1989 & 64.8 & 9.3 & 26.0 \\
1990 & 67.8 & 10.0 & 22.2 \\
1991 & 72.4 & 16.2 & 11.3 \\
1992 & 68.3 & 17.6 & 14.1 \\
1993 & 62.8 & 20.3 & 16.9 \\
1994 & 77.0 & 16.8 & 6.2 \\
1995 & 79.6 & 15.4 & 5.0 \\
1996 & 75.5 & 13.5 & 11.1 \\
1997 & 67.3 & 13.5 & 19.2 \\
1998 & 75.1 & 16.9 & 7.9 \\
$1980-1998$ & 71.4 & 14.8 & 13.8 \\
$1980-1989$ & 70.2 & 13.4 & 16.4 \\
$1990-1998$ & 72.1 & 15.6 & 12.3 \\
$1980-1992$ & 70.0 & 13.8 & 16.2 \\
$1993-1998$ & 72.9 & 15.8 & 11.3 \\
\hline
\end{tabular}

Fuente: Contraloría General de la República de Colombia.
CUADRO A.2

Colombia: Participación del gasto de la Fuerza Pública en el PIB (Porcentajes)

\begin{tabular}{lcccc}
\hline & Remuneración & Operación & Inversión & Total \\
\hline 1980 & 1.2 & 0.4 & 0.2 & 1.8 \\
1981 & 1.3 & 0.3 & 0.1 & 1.8 \\
1982 & 1.3 & 0.3 & 0.1 & 1.7 \\
1983 & 1.6 & 0.4 & 0.2 & 2.2 \\
1984 & 1.6 & 0.2 & 0.5 & 2.3 \\
1985 & 1.5 & 0.3 & 0.3 & 2.1 \\
1986 & 1.4 & 0.2 & 0.4 & 1.9 \\
1987 & 1.4 & 0.2 & 0.3 & 2.0 \\
1988 & 1.4 & 0.2 & 0.5 & 2.1 \\
1989 & 1.4 & 0.2 & 0.6 & 2.2 \\
1990 & 1.4 & 0.2 & 0.5 & 2.1 \\
1991 & 1.5 & 0.3 & 0.2 & 2.0 \\
1992 & 1.6 & 0.4 & 0.3 & 2.3 \\
1993 & 1.8 & 0.6 & 0.5 & 2.9 \\
1994 & 2.0 & 0.4 & 0.2 & 2.6 \\
1995 & 2.2 & 0.4 & 0.1 & 2.8 \\
1996 & 2.6 & 0.5 & 0.4 & 3.4 \\
1997 & 2.4 & 0.5 & 0.7 & 3.6 \\
1998 & 2.5 & 0.6 & 0.3 & 3.4 \\
$1980-1998$ & 1.8 & 0.4 & 0.3 & 2.5 \\
$1980-1989$ & 1.4 & 0.3 & 0.3 & 2.0 \\
$1990-1998$ & 2.1 & 0.5 & 0.4 & 2.8 \\
$1980-1992$ & 1.4 & 0.3 & 0.3 & 2.1 \\
$1993-1998$ & 2.3 & 0.5 & 0.4 & 3.1 \\
\hline
\end{tabular}

Fuente: Contraloría General de la República de Colombia. 


\section{Bibliografía}

Abell, J. (1988): Defense spending and unemployment rates: An empirical analysis disagregated by race, Journal of Conflict Resolution, vol. 32, $\mathrm{N}^{\circ}$ 1, Dorchester, Reino Unido, Dorset Press.

Ball, N. (1983): Defense and development: A critique of the Benoit study, Economic Development and Cultural Change, vol. 31, $\mathrm{N}^{\circ} 3$, Chicago, Illinois, The University of Chicago.

(1986): Gastos militares, relaciones económicas internacionales y distensión, Comercio exterior, volumen $36, \mathrm{~N}^{\circ} 12$, México, D.F.

(1988): Security and Economy in the Third World. Princeton, New Jersey, Princeton University Press.

Bayoumi, T., D. Hewitt y S. Symansky (1993): The Impact of Worldwide Military Spending Cuts on Developing Countries, IMF working paper, $\mathrm{N}^{\circ} 86$, Washington, D.C., Fondo Monetario Internacional (FMI).

Beenstock, M. (1993): International patterns in military spending, Economic Development and Cultural Change, vol. 41, N ${ }^{\circ} 3$, Chicago, Illinois, The University of Chicago.

Benoit, E. (1973): Defense and Economic Growth in Developing Countries, Lexington, Massachusetts, Lexington Books.

Benoit, E. y K. Boulding (1963): Disarmament and the Economy, Nueva York, Harper and Row.

Borner, S., A. Brunotti y B. Weder (1992): Institutional Obstacles to Latin American Growth, Ocassional papers, ํㅜ 24, Ciudad de Panamá, Centro Internacional para el Desarrollo Económico (CINDE).

Brito, D. y M.D. Intriligator (1989): An economic model of guerrilla warfare, International Interactions, vol. $15, \mathrm{~N}^{\circ} 3$.

Brommelhorster, J. (1996): Changing Priorities of Military Expenditures and the Results of the Peace Dividend, Bonn, Alemania, Bonn International Center for Conversion.

Carranza, M. (1986): El desarme y el desarrollo mundial desde la perspectiva latinoamericana, Comercio exterior, vol. $36, \mathrm{~N}^{\circ}$ 12, México, D.F.

Centro Regional de las Naciones Unidas para la Paz, el Desarme y el Desarrollo en América Latina y el Caribe (1994): Proliferación de armamentos y medidas de fomento de la confianza y la seguridad en América Latina, Lima.

Colombia, Ministerio de Hacienda, Comisión del Gasto Público (1986): Informe final 1986, Santafé de Bogotá.

Colombia, Ministerio de Defensa Nacional (1991): Plan quinquenal para la Fuerza Pública: 1992-1996, Documento CONPES, $\mathrm{N}^{\circ} 2570$, Santafé de Bogotá, Consejo Nacional de Política Económica y Social (CONPES).

(1994): Memoria al Congreso, Santafé de Bogotá.

(1995a): La defensa nacional y las Fuerzas Militares, Documento CONPES, $N^{\circ} 2824$, Santafé de Bogotá, CONPES, noviembre.

(1995b): Modernización de la Policía Nacional en el marco del plan de seguridad ciudadana, Documento CONPES, $\mathrm{N}^{\circ} 2771$, Santafé de Bogotá, CONPES, marzo.

Comisión de Racionalización del Gasto y de las Finanzas Públicas (1997): Defensa, seguridad ciudadana y gasto público, Santafé de Bogotá.

Davis, P. K. (1994): New Challenges for Defense Planning. Rethinking How Much is Enough, Santa Mónica, California, Rand.

Deger, S. (1986): Military Expenditure in Third World Countries, Londres, Routledge \& Kegan Paul.

(1992): Military expenditure and economic development: Issues and debates, Military Expenditure and Economic Development, World Bank discussion papers, $\mathrm{N}^{\circ} 185$, Washington D.C., 1992, Banco Mundial.
Dunne, P. (1990): The political economy of military expenditure: An introduction, Cambridge Journal of Economics, vol. 14, $\mathrm{N}^{\circ} 4$, Cambridge, Reino Unido, Academic Press Limited, diciembre.

Estados Unidos, U.S. Arms Control and Disarmament Agency (1996): World Military Expenditures and Arms Transfers, Washington, D.C.

Frederiksen, P. y R. Looney (1982): Defense expenditures and economic growth in developing countries: Some further empirical evidence, Journal of Economic Development, $\mathrm{N}^{\circ} 7$, julio.

Gabriel, R. y P. Savage (1978): Crisis in Command. Mismanagement in the Army, Nueva York, Hill and Wang.

Gansler, J. (1991): Affording Defense, Cambridge Massachusetts, The MIT Press.

Guio Rodríguez, E. A. (1996): Impuesto de guerra: por una sola vez... ¿otra vez?", La semana económica de la ASOBANCARIA, $\mathrm{N}^{\circ} 63$, Santafé de Bogotá, Asociación Bancaria (ASOBANCARIA).

Hayes, M. (1976): Policy consequences of military participation in politics: An analysis of tradeoffs in Brazilian federal expenditures, Comparative Public Policy, Nueva York, Wiley.

Heller, P. y J. Diamond (1990): International Comparisons of Government Expenditure Revisited: The Developing Countries, 1975-86, IMF ocassional paper, Nº 69, Washington, D.C., FMI, abril.

Hewitt, D. (1991): Military Expenditure: International Comparison of Trends, IMF working paper, $\mathrm{N}^{\circ} 54$, Washington, D.C., Fondo Monetario Internacional, mayo.

(1993): The Reasons Behind the Post-1985 Fall in World Military Spending, IMF working paper, $\mathrm{N}^{\circ} 18$, Washington, D.C, FMI, mayo.

Hoffman, B. y J. Morrison Taw (1992): A Strategic Framework for Countering Terrorism and Insurgency, Santa Mónica, California, Rand.

Hooker, R. (1993): Maneuver Warfare: An Anthology, California, Presidio Press.

Kaun, D. (1988): War and Wall Street: The impact of military conflict on investor attitudes, Journal of Conflict Resolution, vol. 32, $\mathrm{N}^{\circ} 1$, Dorchester, Reino Unido, Dorset Press, marzo.

Klein, L. (1986): El desarme y el desarrollo socioeconómico, Comercio exterior, vol. 36, $\mathrm{N}^{\circ} 12$, México, D.F., diciembre.

Knight, M., N. Loayza y D. Villanueva (1996): The Peace Dividend: Military Spending Cuts and Economic Growth, Staff papers, vol. 43, $\mathrm{N}^{\circ} 1$, Washington, D.C., FMI, marzo.

Leger R. (1993): World Military and Social Expenditures, Washington, D.C., U.S. Arms Control and Disarmament Agency, U.S. Government Printing Office.

Leontief, W. y F. Duchin (1983): Military Spending, Oxford, Reino Unido, Oxford University Press.

Looney, R.E. (1986): The Political Economy of Latin American Defense Expenditures. Case Studies of Venezuela and Argentina, Lexington, Massachusetts, Lexington Books, D.C. Heath and Company.

Nabe, O. (1983): Military expenditure and industrialization in Africa, Journal of Economic Issues, vol. 17, $\mathrm{N}^{\circ} 2$, junio.

Ospina Sardi, J.(1991): Bases para el Plan Estratégico de Desarrollo de las Fuerzas Armadas 1991-1995, Santafé de Bogotá, Departamento Nacional de Planeación.

Paret, P. (1986): Makers of Modern Strategy: from Machiavelli to the Nuclear Age, Princeton, New Jersey, Princeton University Press.

Pivetti, M. (1992): Military spending as a burden on growth: An underconsumptionist critique, Cambridge Journal of Economics, vol. 16, Nㅜ 4, Cambridge, Reino Unido, Academic Press Limited. 
Ponton Laverde, G. (1968): Apuntes sobre economía de guerra, Revista de las Fuerzas Armadas, vol. 18, N 52, Santafé de Bogotá, Imprenta y Publicaciones de las Fuerzas Militares.

Porter, R. (1989): Recent trends in LDC military expenditures, World Development, vol. 17, $\mathrm{N}^{\circ} 10$, Oxford, Reino Unido, Pergamon Press, octubre.

Rasier, K. y W. Thompson (1988): Defense burdens, capital formation, and economic growth: The systemic leader case, Journal of Conflict Resolution, vol. 32, $\mathrm{N}^{\circ} 1$, Sage Publications Inc., marzo.

Restrepo Salazar, J.C. y L.I. Betancur Escobar (1995): Aspectos económicos del conflicto colombo-peruano 1932-1934, Santafé de Bogotá, Ministerio de Defensa Nacional, Fondo Rotatorio de la Policía Nacional.

Ruiz Nova, A. (1997): Defensa, seguridad ciudadana y gasto público, Revista de las Fuerzas Armadas, vol. 52, ํㅜ 162, Santafé de Bogotá, Imprenta y Publicaciones de las Fuerzas Militares.

Sandler, T. y K. Hartley (1995): The Economics of Defense, Londres, Cambridge University Press.

Scheetz, T. (1990): El costo laboral de la seguridad externa e interna: los casos de la Argentina, Chile, Paraguay y Perú, 19691988, Desarrollo económico, vol. 30, № 118, Buenos Aires, Instituto de Desarrollo Económico y Social (IDES)

(1991): The macroeconomic impact of defense expenditures: Some econometric evidence for Argentina, Chile, Paraguay and Peru, Defense Economics, vol. 3, Londres, Duckworth.
(1993): El marco teórico, político y económico para una reforma militar en la Argentina, Serie de documentos de trabajo, $\mathrm{N}^{\circ} 50$, Buenos Aires, Centro de Investigaciones Europeo-Latinoamericanas (EURAL).

Schelling, T.C. (1980): The Strategy of Conflict, Cambridge, Massachusetts, Harvard University Press.

Smith, R. (1977): Military expenditure and capitalism, Cambridge Journal of Economics, vol. 1, $\mathrm{N}^{\circ} 1$, Cambridge, Reino Unido, Academic Press Limited, marzo.

Smith, D. y R. Smith (1986): La economía del militarismo, Madrid, Editorial Revolución S.A.L.

Soto, A. (1991): La seguridad y la defensa en América Latina en los años noventa: retos y perspectivas. Documentos ocasionales, $\mathrm{N}^{\circ}$ 24, Santafé de Bogotá, Universidad de los Andes, Centro de Estudios Internacionales, noviembre-diciembre.

Thee, M. (1986): Carrera armamentista y tecnología y estrategia militares, Comercio Exterior, vol. 36, ํㅜ 12, México, D.F., diciembre.

Thompson, E. (1974): Taxation and national defense, Journal of Political Economy, vol. 82, Chicago, Illinois, The University of Chicago Press, julio-agosto.

Viñas, A. (1985): Principales interacciones del gasto militar y el subdesarrollo. Un resumen de la literatura reciente, Comercio Exterior, vol. 35, $\mathrm{N}^{\circ} 3$, México, D.F., marzo.

Wulf, H. (1980): Transnational Arms Production Technology, Hamburgo, University of Hamburg, Institut fur Friedensforschun un Sicherheltspolitik. 